\title{
DESIGN OF A POTENTIAL METHOD OF PRODUCING NANOSUSPENSIONS USING CRYOPROTECTANTS IN NANOPRECIPITATION METHOD
}

\author{
Sravya Maddukuri*1 \& Radha GV \\ 'Department of Pharmaceutics, M L R Institute of pharmacy, \\ Hyderabad, Telangana, India \\ 2Department of Pharmaceutics, Gitam Institute of Pharmacy, \\ Visakhapatnam, Andhra Pradesh, India.
}

\begin{abstract}
Azalide antibiotic, azithromycin dihydrate has limited applications in clinical pharmacy, due to its low bioavailability. Nanosuspensions, due to its advantages such as enhanced surface area and surface free energy, has been used as a technique to improve its oral bioavailability. In this work, 12 nanosuspension formulations were developed with three different stabilizers- poloxamer188, poloxamer 407 and PVP in two concentrations, out of which six nanosuspensions were formulated using nanoprecipitation technique(PNS 1-PNS6) and six nanosuspensions were formulated using nanoprecipitation followed by addition of mannitol as a cryoprotectant during the freeze-drying process (FNS1-FNS6). Prepared nanosuspensions by above mentioned techniques were evaluated, characterized and compared with each other by X-ray diffractometry (XRD), Fourier-transform infra-red (FT-IR) spectroscopy, Scanning Electron Microscopy (SEM) images, In - Vitro dissolution profile. FTIR studies confirmed that there was no distinguishable physical or chemical interaction between drug and excipients used for this study. SEM images showed the surface morphology to be accurate and size to be in nanometer range. XRD data confirmed slight changes in the crystallinity of azithromycin dihydrate in the formulations of nanosuspensions, to which improvement in solubility pattern can be attributed. Nanosuspensions containing azithromycin dihydrate and poloxamer 188 (FNS1 and FNS2) in molar ratios of 1:1 and 1:2, which are prepared by nanoprecipitation method including mannitol as a cryoprotectant, were found to be better than other formulations. In vitro studies reveal that there is a distinguishable increase in the dissolution rate of azithromycin in freeze-dried nanosuspensions when compared to pure azithromycin. It could be concluded that addition of mannitol or any other cryoprotectants during freeze-drying of nanosuspensions can prove beneficial in terms of improvement of bioavailability, change in crystallinity, and stability profile.
\end{abstract}

Keywords: Nanosuspensions, Cryoprotectants, Nanoprecipitation method, Bioavailability enhancement, Azithromycin dihydrate, Nanoparticles. 


\section{Introduction}

Azithromycin dihydrate is a poorly watersoluble macrolide antibiotic, which had been most widely used in the treatment of bacterial infections. The water solubility of this well-known antibiotic has been limited and hence belongs to Biopharmaceutical Classification System Class II(BCS class II). The absolute bioavailability of azithromycin dihydrate following oral administration of $250 \mathrm{mg}$ capsules was approximately reported to be $34 \%$ '. Thus, improvement of bioavailability has been a priority for this research work.

Nanoparticles/Nanotechnology are the most promising technology over the past 25 years of research, finds uses in oral, parenteral, transdermal, transmucosal, and many other routes of drug delivery. Over the last decade, nanoparticle engineering had been developed and reported for pharmaceutical applications. There are many advantages of nanosuspension such as increased rate of absorption, increased oral bioavailability, rapid onset of action, reduction in required dose, reduction in fed/fasted variability, high drug loading capacity, suitability for hydrophilic drugs, dose reduction is possible, enhancing the physical and chemical stability of drugs ${ }^{2-4}$.

Nanosuspensions are submicron colloidal dispersions of nanosized drug particles stabilized by surfactants ${ }^{5}$. Nanosuspensions consist of the poorly water-soluble drug without any matrix material suspended in dispersion 6. Methods of manufacture involve crystallization, building nanocrystals up from the supersaturated solution state, as well as making larger particles smaller by homogenization or milling ${ }^{7}$. Out of topdown approaches and bottom-up approaches available for the preparation of nanosuspensions, the simplest method to prepare drug-loaded nanoparticles is the nanoprecipitation or solvent displacement method, developed by Fessi et $\mathrm{a}{ }^{8}$. Nanoprecipitation method involves precipitation of drug into finely divided nano-sized particles, by addition of an aqueous solvent into a non-aqueous solvent that is miscible with each other, but results in the spontaneous formation of nanosuspensions under continuous agitation. A modified nanoprecipitation method involves the addition of cryoprotectants during freeze-drying process employed for drying of nanoparticles?.

Nanoparticles produced by nanoprecipitation technique were prone to significant agglomeration, causing changes in particle size after the drying process. During freeze-drying, the formation of ice crystals was believed to cause damage to the basic physiochemical properties of nanoparticles. Aim of this work was to investigate the protective action of cryoprotectants on nanoparticles. Mechanism of action of cryoprotectants has been reported by Venkata Bharadwaz Vedula et al ${ }^{10}$. It has been reported that cryoprotectants partially solubilizes the nanoparticles so that they are less prone to puncture and interrupts the lattice formation of ice so that the occurence of crystals could be controlled. Mannitol was added during freeze-drying, to act as cryoprotectants and to prevent particle agglomeration.

A comparative analysis between nanosuspensions prepared by nanoprecipitation technique followed by conventional methods of drying and nanosuspensions prepared by nanoprecipitation technique, followed by freeze-drying with the addition of mannitol as cryoprotectants was attempted. As 
mentioned earlier, nanosuspensions have this major drawback of particle agglomeration; hence, to avoid such instability problems, an attempt was made to formulate nanosuspensions with cryoprotectants during the freeze-drying process.

\section{MATERIALS AND METHODS:}

All the materials used for the research were of analytical grade purity. Azithromycin dihydrate was a kind gift from Aurobindo Pharma Ltd. Poloxamer 188(Pluronic®F188), Poloxamer 407(Pluronic $\AA F-407)$ were obtained as gift samples from BASF India Itd; Acetone, methanol, ethanol, PVP used in this work were obtained from Qualichems, Fischer scientific, Changshu yangyuan chemical, Oxford laboratory respectively. Distilled water was used to prepare aqueous solutions and was obtained by a suitable process.

\section{METHODS}

Determination of $\lambda$ max: As a part of preliminary studies, $\lambda$ max of the drug was found out using a stock solution of 1 $\mathrm{mg} / \mathrm{ml}$, first by dissolving the drug in a small quantity of methanol and diluted with 100 $\mathrm{ml}$ of phosphate buffer (pH 6.8). The stock solution was serially diluted to get solutions in the range of $2-12 \mu \mathrm{g} / \mathrm{ml}$ and, $\lambda$ max of the solution was found out by scanning from $200-400 \mathrm{~nm}$ in a double beam UVVisible spectrophotometer.

\section{Determination of Calibration Curve}

The stock solution of $1 \mathrm{mg} / \mathrm{ml}$ of azithromycin dihydrate was prepared. The stock solution was serially diluted to get solutions in the range of $2-20 \mu \mathrm{g} / \mathrm{ml}$. The absorbances of the different diluted solutions have been measured in a double beam UV-Visible spectrophotometer at 210 nm. A calibration curve was plotted by taking the concentration of solution on the $X$-axis and absorbance on the $Y$-axis and correlation coefficient ' $R$ 2' was calculated.

\section{Determination of Melting Point:}

The melting point of the drug has been determined by taking a small amount of the drug in a capillary tube that was closed at one end. The capillary tube was placed in a thermionic melting point apparatus and, the temperature at which the drug melted was noted. Averages of three readings were taken.

\section{Drug excipients interaction study by FTIR:}

FTIR emission spectrometer (Shimadzu, Japan) was used to record the FTIR spectrum of the drugs from 400 to $4000 \mathrm{~cm}$ 1 to confirm compatibility between the excipients used and pure drug in the formulation. FTIR spectra of pure drug, along with physical mixture of polymers and drug were taken separately. The sample was grounded with $\mathrm{KBr}$ and pressed to a suitablesize disk for measurement.

\section{PREPARATION OF NANOSUSPENSIONS}
Preparation of nanosuspensions by nanoprecipitation method ${ }^{11}$ :

Azithromycin dihydrate nanosuspensions have been successfully prepared by nanoprecipitation

technique.

Nanoparticles have been spontaneously formed when the organic phase (acetone) containing Hydroxy propyl methyl cellulose and druglas per formulae in formulation table) was injected dropwise using a syringe into continually stirred aqueous phase containing different ratios of stabilizers Poloxamer 188/ Poloxamer 407/ PVP. Nanoparticles were spontaneously formed and, the resultant solution 2020 May Edition | www.jbino.com | Innovative Association 
changed turbid. Further size reduction of the particles could be obtained by homogenization of the obtained solution using homogenizer. The organic phase was removed by continuing stiring for 4 hours. (Table 1) The final product was allowed to dry under ambient conditions for further evaporation of the organic phase, i.e., acetone and further dried at $40{ }^{\circ} \mathrm{C}$ to obtain free flowing nanosuspensions of azithromycin dihydrate.

$\begin{array}{lcr}\text { Preparation of } & \text { nanosuspensions by } \\ \text { nanoprecipitation } & \begin{array}{c}\text { method with } \\ \text { cryoprotectants }\end{array}{ }^{12} \text { : } & \text { Nanoprecipitation }\end{array}$
method was slightly modified to include the process of lyophilization and cryoprotectants such as mannitol. Hydrophobic drug (Azithromycin dihydrate) has been dissolved in organic phase consisting of acetone and HPMC (Hydroxy propyl methyl cellulose). Polymers (Poloxamer 188/ Poloxamer 407/ PVP) were dissolved in aqueous phase consisting of distilled water. The organic phase was then added dropwise using syringe to aqueous phase under continuous stirring. Nanoparticles were spontaneously formed, and the resultant solution changed turbid. Further size reduction of the particles can be obtained by homogenization of the resultant solution using homogenizer (Table 2). The organic phase was removed by continuing stirring for 4 hours. The dispersion was finally lyophilized (penguin classic plus, $6 \mathrm{~kg}$ freeze dryer) for $9 \mathrm{~h}$ to yield freezedried nanoparticles. During the process of freezing (as an initial step for lyophilization), different concentrations of mannitol in $10 \%$ and $20 \% \mathrm{w} / \mathrm{w}$ of the total weight of solid content were added into nanodispersion to act as cryoprotectants. Samples were frozen at $-70^{\circ} \mathrm{C}$ and placed immediately in the freeze-drying chamber.

\section{CHARACTERIZATION AND EVALUATION OF NANOSUSPENSIONS:}

\section{Drug Content:}

An accurately weighed quantity of nanosuspension equivalent to $100 \mathrm{mg}$ of azithromycin was taken into a $100 \mathrm{ml}$ volumetric flask, dissolved in methanol and suitably diluted with $6.4 \mathrm{pH}$ Phosphate buffer. The content of azithromycin was determined spectrophotometrically at $201 \mathrm{~nm}$ against suitable blank using UVvisible spectrophotometer and the amount of drug in each formulation was calculated.

\section{Solubility Studies:}

Solubility studies have been performed according to the method reported by Higuchi and Connors ${ }^{13-15}$. Excess (usually more than $1 \mathrm{mg} / \mathrm{ml}$ concentration) of drug was added to $25 \mathrm{ml}$ of distilled water containing varying amounts of poloxamer 188, poloxamer 407 and poly ethylene glycol 20,000such as 0, 2, 4, 6, 8, and 10 millimoles/liter, taken in stoppered conical flasks and mixtures have been shaken for $24 \mathrm{hrs}$ in rotary flask shaker. After shaking to achieve equilibrium, $2 \mathrm{ml}$ of aliquots were withdrawn at $1 \mathrm{hr}$ intervals and filtered through whatman filter paper. The filtrate was diluted if necessary and analyzed by UV-spectrophotometer at $201 \mathrm{~nm}$. Shaking has been continued until three constitutive readings were the same. The apparent stability constants (1:1) could be calculated from the phase solubility diagrams, according to the following equation:

$K_{c}=\frac{\text { Slope }}{S_{0}(1-\text { Slope })}$

Where $\mathrm{Kc}=$ apparent stability constant, $S_{0}=$ Intercept 


\section{In Vitro Dissolution Studies of Inclusion Complexes}

Quantity of nanosuspensions equivalent to $20 \mathrm{mg}$ of azithromycin was filled in hard gelatin capsule by hand filling method. The dissolution study of capsules has been conducted using dissolution testing USP apparatus I (basket method) in $900 \mathrm{ml}$ of $6.4 \mathrm{pH}$ Phosphate buffer at $37 \pm 0.5^{\circ} \mathrm{C}$ and at a speed of $50 \mathrm{rpm}$. Aliquot of $5 \mathrm{ml}$ was withdrawn at a predetermined time interval and, equivalent amount of fresh medium was replaced to maintain a constant volume after each sampling and analyzed spectrophotometrically at 201 $\mathrm{nm}$ against suitable blank using UV-visible spectrophotometer. The amount of azithromycin dihydrate released from each nanosuspension has been calculated and plotted against time and compared with pure drug.

\section{Kinetics of In Vitro Drug Release}

To study the release kinetics of in vitro drug release, data obtained from in vitro release study were plotted in various kinetic models: Zero order as \% drug released versus time, First order as log \% drug retained versus time, Higuchi as \% drug released versus $\sqrt{t i m e}$, Korsmeyer-Peppas as log \% drug released versus log time.

\section{X-Ray Diffraction Study}

Vacuum grease was applied over a glass slide to adhere to the sample. About $100 \mathrm{mg}$ of sample was sprinkled over it to make a layer with a thickness of $0.5 \mathrm{~mm}$. All the experiments have been performed on an XRD instrument (Japan Science D/max 2500 ) with a sensitivity of 0.001 . The samples have been exposed to CuKa radiation under $40 \mathrm{kV}$ and $40 \mathrm{~mA}$ over the $2 \theta$ range from $5^{\circ}$ to $90^{\circ}$ in increments of $0.12^{\circ} / \mathrm{s}$ every $0.02^{\circ}$. The samples used for this study were freshly prepared (48 $\mathrm{h}$ prior) and preserved in a desiccator before use.

\section{Scanning Electron Microscopy (SEM)}

The surface morphology of the nanosuspensions was studied using a scanning electron microscope (JSM-5610 LV Jeol, Japan). The samples were coated with platinum to provide a conductive layer for observing images at $15 \mathrm{kV}$.

\section{Poly Dispersity Index (PDI):}

Mean particle size and Polydispersity index (PDI) or heterogeneity index of prepared Nanosuspension have been obtained using Zetatrac. After suitable dilution, prepared nanosuspension has been added to the sample cell and, determination was carried out.

\section{Particle Size Distribution and Zeta Potential Analysis:}

Particle size, size distribution and zeta potential of nanosuspension has been determined using Zetatrac (Microtrac Inc., USA). Zetatrac utilizes a high-frequency AC electric field to oscillate the charged particles. The Brownian motion power spectrum was analyzed with modulated power spectrum technique, a component of the power spectrum resulting from oscillating particles. Nanosuspensions equivalent to $100 \mathrm{mg}$ of sample have been suspended with sufficient water; samples were directly placed into cuvette and particle size, size distribution, as well as zeta potential, have been measured.

\section{RESULTS AND DISCUSSION:}

\section{UV Spectrum of Azithromycin Dihydrate}

From the stock solution - $1000 \mu \mathrm{g} / \mathrm{ml}$ azithromycin dihydrate solution, suitable dilutions were made to obtain $12 \mu \mathrm{g} / \mathrm{ml}$ 
solution of azithromycin dihydrate. This solution has been scanned for maximum absorption wavelength using UVspectrophotometer in the range of 200$400 \mathrm{~nm}$. The absorption maxima for Azithromycin dihydrate were found to be $201 \mathrm{~nm}$ (Figure 1), and hence, the same was used as $\lambda$ max for estimation of azithromycin dihydrate in this work. The standard graph and entire analysis were performed in a $\mathrm{pH} 6.8$ phosphate buffer.

\section{Calibration curve of azithromycin dihydrate:}

The standard concentrations of azithromycin dihydrate have been prepared in $\mathrm{pH} 6.8$ phosphate buffer, and absorbance was measured at $201 \mathrm{~nm}$. The observations are tabulated (Table 3). The standard graph of azithromycin dihydrate in $\mathrm{pH} 6.8$ phosphate buffer showed linearity with $R^{2}$ value 0.9994 in the concentration range of $4-20 \mu \mathrm{g} / \mathrm{ml}$.

\section{Melting Point Determination}

The melting point of Azithromycin dihydrate was found to be $114^{\circ} \mathrm{C}$, which correlates with a standard melting point value of azithromycin dihydrate indicating the purity of the drug sample.

\section{COMPATIBILITY STUDIES:}

\section{Fourier Transform Infrared spectroscopic studies}

FT-IR spectra were performed for pure drug as well as the physical mixture of the pure drug and stabilizers used in the study. The FTIR spectra of pure Azithromycin dihydrate (Figure 2) showed characteristic peaks at $1368.72 \mathrm{~cm}-1 \quad$ (C-N-stretching), 2958.90 cm-1 (C-H-stretching), $1379.15 \mathrm{~cm}-1$ (CHO-stretching alcoholic group), 1545.03 $\mathrm{cm}-1$ ( $\mathrm{C}=\mathrm{O}$-stretching amidic group), $3471.98 \mathrm{~cm}-1$ (N-H-stretching), $1707.06 \mathrm{~cm}$ -
1 (C=C-bending), $794.70 \quad \mathrm{~cm}-1 \quad$ (C-Fstretching), $1122.61 \mathrm{~cm}-1$ (O-H-bending).

The FTIR spectra of Azithromycin dihydrate in combination with stabilizers were having similar fundamental peaks and pattern when compared with the pure drug with no significant changes (Figure 2).

\section{PREPARATION OF AZITHROMYCIN NANOSUSPENSIONS}

Nanosuspensions of azithromycin dihydrate have been prepared by two methodsnanoprecipitation and modified nanoprecipitation method with the use of cryoprotectants, including drug stabilizers such as Poloxamer 188, Poloxamer 407 and PVP in ratio 1:1 and1:2. Drug content values for all nanosuspension formulations were found to be in the range of 97.5$99.87 \%$.

\subsubsection{PHASE SOLUBILITY STUDIES:}

As a preliminary study for carrying out the preparation of nanosuspensions, Phase solubility analysis was carried out as per the method reported by Higuchi and Connors. Pure drug solubility was found to be $0.085 \mathrm{mg} / \mathrm{ml}$. From these phase solubility studies carried out over 24 -72 hours, Physical mixtures of drug and Poloxamer 188 has shown highest drug solubility when compared to the mixtures of pure drug and poloxamer 407 and PVP. The filtrate was diluted if necessary and analyzed by UV-spectrophotometer at $201 \mathrm{~nm}$. Shaking was continued until three constitutive readings were same.

Correlation coefficients $\left(R^{2}\right)$ were 0.797, $0.801,0.8421$ for phase solubility diagrams of pure drug along with PVP, poloxamer 407 and poloxamer 188 respectively. Solubility of pure drug was found linearly increasing upto a certain point of concentration of carriers, hence solubility 
curve was assumed to follow $B_{s}$ type of diagram, suggesting pure drug has some but limited solubility in the carriers. These carriers can be ranked according to the effect of carriers on solubility of pure drug as: Poloxamer 188> Poloxamer 407> PVP Apparent solubility/stability constants for Poloxamer 188, Poloxamer 407 and PVPcould not be calculated, since the exact stoichiometric ratio was not known. The results are tabulated in Table 5 and graphical representation was shown in Figure 3.

\subsubsection{IN VITRO DISSOLUTION STUDIES FOR NANOSUSPENSIONS}

The drug release data obtained for both methods nano precipitation and Nano precipitation method with cryoprotectants method formulations (PNS1-PNS6 and FNS1FNS6) are shown in figures 4 and 5 . It shows the cumulative percent drug released as a function of time for all formulations. In vitro studies reveal that there is marked increase in the dissolution rate of azithromycin in freeze dried nanosuspensions, when compared to pure azithromycin after 12 hrs. From the in vitro drug release profile, it can be seen that formulation FNS1 and FNS2 were found to have drug release of 98.37 and $97.42 \%$ respectively, followed by other formulations of nanosuspensions. This may be attributed to the increase in drug wettability, conversion to amorphous form and solubilization of the drug due to hydrophilic carrier.

\section{Release Order Kinetics of Optimized Azithromycin Dihydrate Nanosuspensions}

From the results it is apparent that the regression coefficient value closer to unity in case of zero order plot i.e. 0.97, 0.963, $0.963,0.959$ indicates that the drug release follows a Zero order mechanism. The mass transfer with respect to square root of the time has been plotted, revealed a linear graph with regression value, stating that the release from the matrix was through diffusion. Further the $\mathrm{n}$ value obtained from the Korsmeyer plots i.e. 0.736, 0.756, 0.772 0.785 suggest that the drug release from nanosuspensions was anomalous Non fickian diffusion (Table 6).

\section{$X$ Ray Diffractograms of Nanosuspensions}

The optimized Azithromycin Nano suspension was analyzed to find out whether the Nanosuspensions of various drug polymer ratios are crystalline or amorphous. The presence of numerous distinct peaks in the XRD spectrum indicates that Azithromycin was present as a crystalline material. The XRD patterns depicted by nanosuspensions by two methods reveal a decrease in the number of peaks which probably represents decrease in crystallinity. $X$ Ray Diffractograms of optimized nano suspension was characterized by the marked reductions in crystalline diffraction peaks, which is characteristic of an amorphous compound (Figure 6). The enhancement in the dissolution rate of the drug from the optimized Azithromycin nano suspension is ascribed to the marked reduction in the crystallinity of the drug.

\section{Scanning Electron Microscopy of Optimized Nanosuspensions}

SEM photographs for optimized formulationsFNS1, FNS2 are shown in Figure 7. The drug crystals seemed to be smoothsurfaced, irregular in shape and size. The drug surface in Nano suspension seems to be more porous in nature. The results could be attributed to suspension of the drug in the molten mass of the polymer. 
Particle size of all the formulations ranged

\begin{tabular}{|c|c|c|c|}
\hline Stabiliser & Poloxamer 188 & Poloxamer 407 & PVP \\
& & & \\
\hline
\end{tabular}

Polydispersity Index:

from 70-270 nm (Table 7).

Table 1: organic phase and aqueous phase under ambient conditions

\begin{tabular}{|l|l|}
\hline \multirow{2}{*}{ Organic phase } & $10 \mathrm{ml}$ of acetone \\
\cline { 2 - 2 } & HPMC (Hydroxy propyl methyl cellulose) \\
\cline { 2 - 2 } & Azithromycin dihydrate \\
\hline Aqueous phase & $\begin{array}{l}\text { Stabilizers (Poloxamer 188/ Poloxamer 407/ } \\
\text { PVP) }\end{array}$ \\
\cline { 2 - 2 } & $20 \mathrm{ml}$ of distilled water \\
\hline
\end{tabular}

Table 2: Formulation table of nanosuspensions 


\begin{tabular}{|c|c|c|c|c|c|c|c|c|c|c|c|c|}
\hline $\begin{array}{c}\text { Preparatio } \\
\mathrm{n}\end{array}$ & \multicolumn{2}{|c|}{$\begin{array}{l}\text { Nanoprecipit } \\
\text { ation method }\end{array}$} & \multicolumn{2}{|c|}{$\begin{array}{l}\text { Nanoprecipita } \\
\text { tion method } \\
\text { with } \\
\text { cryoprotectant } \\
\text { s }\end{array}$} & \multicolumn{2}{|c|}{$\begin{array}{c}\text { Nanoprecipit } \\
\text { ation } \\
\text { method }\end{array}$} & \multicolumn{2}{|c|}{$\begin{array}{l}\text { Nanoprecipit } \\
\text { ation method } \\
\text { with } \\
\text { cryoprotectan } \\
\text { ts }\end{array}$} & \multicolumn{2}{|c|}{$\begin{array}{c}\text { Nanoprecipit } \\
\text { ation } \\
\text { method }\end{array}$} & \multicolumn{2}{|c|}{$\begin{array}{l}\text { Nanoprecipi } \\
\text { ation methoc } \\
\text { with } \\
\text { cryoprotecta } \\
\text { nts }\end{array}$} \\
\hline $\begin{array}{l}\text { Formulati } \\
\text { on code }\end{array}$ & PNS1 & $\begin{array}{c}\text { PNS } \\
2\end{array}$ & FNS1 & FNS2 & $\begin{array}{c}\text { PNS } \\
3\end{array}$ & $\begin{array}{c}\text { PNS } \\
4\end{array}$ & FNS3 & $\begin{array}{c}\text { FNS } \\
4\end{array}$ & $\begin{array}{c}\text { PNS } \\
5\end{array}$ & $\begin{array}{c}\text { PNS } \\
6\end{array}$ & $\begin{array}{c}\text { FNS } \\
5\end{array}$ & $\begin{array}{c}\text { FNS } \\
6\end{array}$ \\
\hline $\begin{array}{l}\text { Drug: } \\
\text { Carrier }\end{array}$ & $1: 1$ & $1: 2$ & $1: 1$ & $1: 2$ & $1: 1$ & $1: 2$ & $1: 1$ & $1: 2$ & $1: 1$ & $1: 2$ & $1: 1$ & $1: 2$ \\
\hline
\end{tabular}

Table 3: Standard curve in $\mathrm{pH} 6.8$ phosphate buffer

\begin{tabular}{|lll|}
\hline S.No. & Concentration $(\mu \mathrm{g} / \mathrm{ml})$ & Absorbance \\
\hline $\mathbf{1}$ & $\mathbf{4}$ & $\mathbf{0 . 1 4 8}$ \\
\hline $\mathbf{2}$ & $\mathbf{8}$ & $\mathbf{0 . 3 7 9}$ \\
\hline $\mathbf{3}$ & $\mathbf{1 2}$ & $\mathbf{0 . 5 8 2}$ \\
\hline $\mathbf{4}$ & $\mathbf{1 6}$ & $\mathbf{0 . 7 9 7}$ \\
\hline $\mathbf{5}$ & $\mathbf{2 0}$ & $\mathbf{0 . 9 5 1}$ \\
\hline
\end{tabular}

Table 4: Melting point determination of azithromycin dihydrate

\begin{tabular}{|l|l|l|}
\hline Trial number & Melting point $\left({ }^{0} \mathrm{C}\right)$ & $\begin{array}{l}\text { Average of three } \\
\text { readings }\left({ }^{0} \mathrm{C}\right)\end{array}$ \\
\hline 1 & $\mathbf{1 1 2}$ & $\mathbf{1 1 4}$ \\
\hline 2 & $\mathbf{1 1 4}$ & \\
\hline 3 & $\mathbf{1 1 8}$ & \\
\hline
\end{tabular}

\begin{tabular}{|c|l|l|l|l|}
\hline S.No & Concentration of & Concentration of & Concentration of & Concentration of \\
& poloxamer 407 / PEG & Azithromycin & Azithromycin & Azithromycin \\
& 20,00/ Poloxamer 407 & dihydrate in & dihydrate in PVP & dihydrate in \\
& $(\% \mathrm{w} / \mathrm{v})$ & poloxamer 407 & solutions $(\mathrm{mg} / \mathrm{ml})$ & poloxamer 188 \\
\hline $\mathbf{1}$ & 0 & solutions $(\mathrm{mg} / \mathrm{ml})$ & & solutions $(\mathrm{mg} / \mathrm{ml})$ \\
\hline
\end{tabular}

2020 May Edition | www.jbino.com | Innovative Association 


\begin{tabular}{|c|c|c|c|c|}
\hline $\mathbf{2}$ & 2 & 0.183 & 0.16 & 0.15 \\
\hline $\mathbf{3}$ & 4 & 0.193 & 0.175 & 0.17 \\
\hline $\mathbf{4}$ & 6 & 0.212 & 0.19 & 0.2 \\
\hline $\mathbf{5}$ & 8 & 0.225 & 0.204 & 0.23 \\
\hline $\mathbf{6}$ & 10 & 0.242 & 0.208 & 0.27 \\
\hline
\end{tabular}

Table 5: Solubility studies of azithromycin dihydrate in Poloxamer 188/ PVP/Poloxamer 407

Table 6: Release order kinetics of optimized nanosuspensions with correlation coefficients.

\begin{tabular}{|c|c|c|c|c|c|}
\hline Formulation & Zero order & First order & Higuchi & Korsmeyer-Peppas & $\mathrm{n}$ value \\
\hline FNS1 & 0.97 & 0.843 & 0.872 & 0.859 & 0.736 \\
\hline FNS2 & 0.963 & 0.855 & 0.880 & 0.864 & 0.756 \\
\hline FNS4 & 0.967 & 0.858 & 0.873 & 0.859 & 0.772 \\
\hline FNS6 & 0.959 & 0.861 & 0.873 & 0.857 & 0.785 \\
\hline
\end{tabular}

Table 7: Poly dispersity index of optimised nanosuspensions

\begin{tabular}{|l|l|l|l|}
\hline Formulation code & Particle Size $(\mathrm{nm})$ & PDI or Dispersity & Zeta Potential $(\mathrm{mV})$ \\
\hline FNS 1 & $100-185 \mathrm{~nm}$ & 0.562 & -50 \\
\hline FNS 2 & $70-270 \mathrm{~nm}$ & 0.545 & -48 \\
\hline FNS 4 & $110-250 \mathrm{~nm}$ & 0.591 & -47 \\
\hline
\end{tabular}

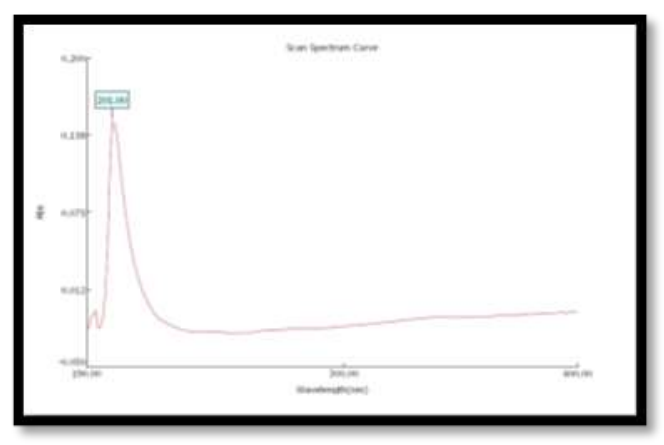

Figure 1: UV spectrum scan of 2020 May Edition | www.jbino.com | Innovative Association 
Azithromycin dihydrate

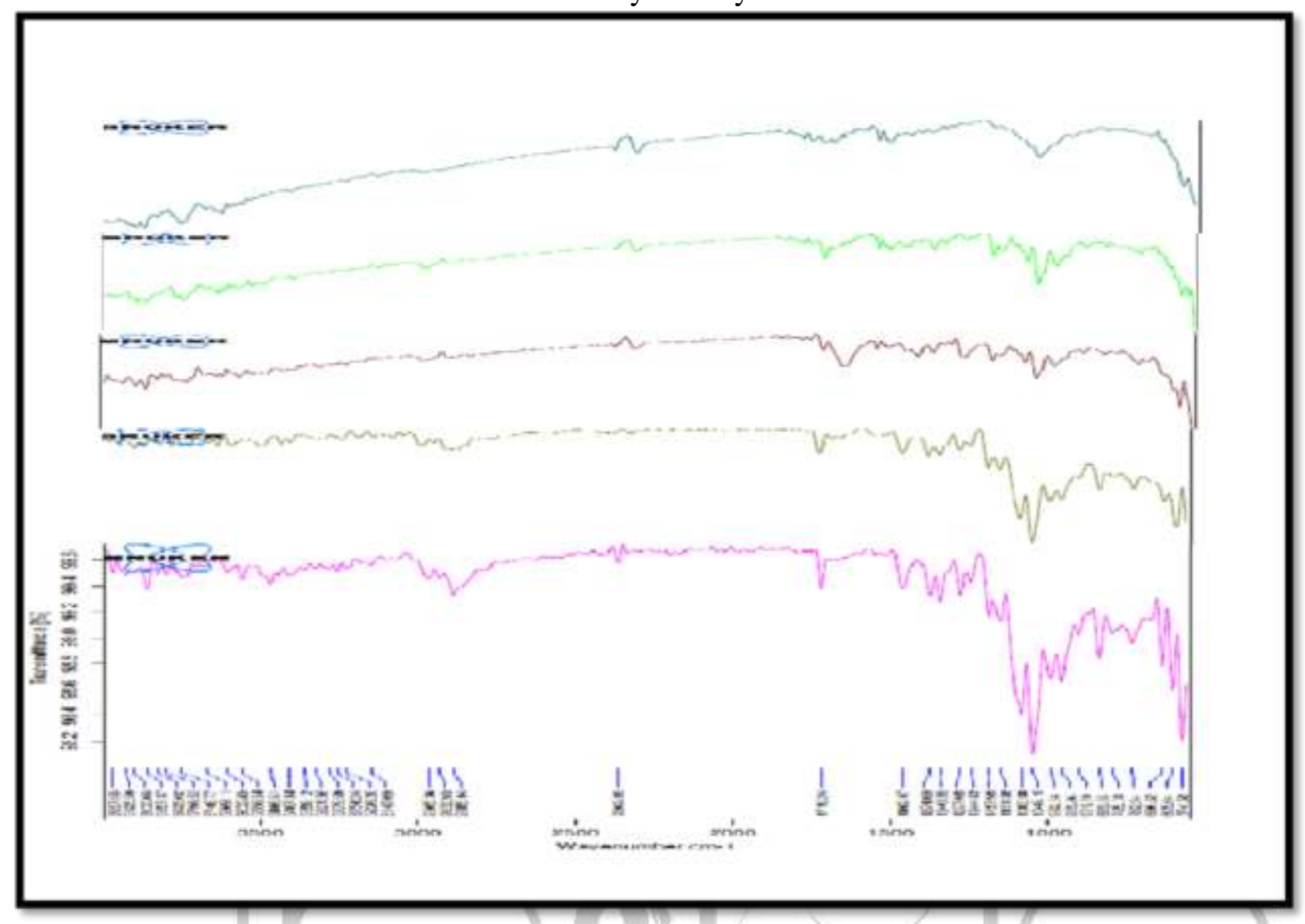

Figure 2: FTIR overlay showing FTIR studies on the pure drug, pure drug + HPMC, Pure drug + Poloxamer 188, Pure drug + Poloxamer 407, Pure drug + PVP from bottom to top

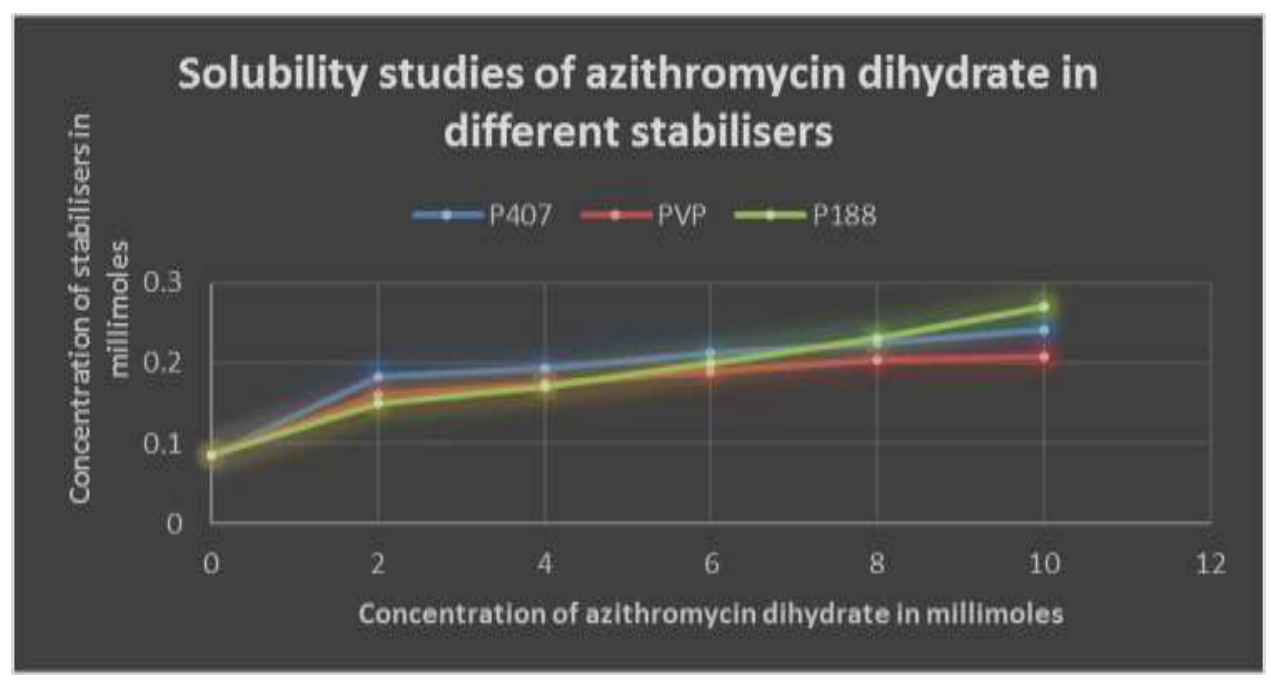

Figure 3: Solubility studies of azithromycin dihydrate in different stabilizers 


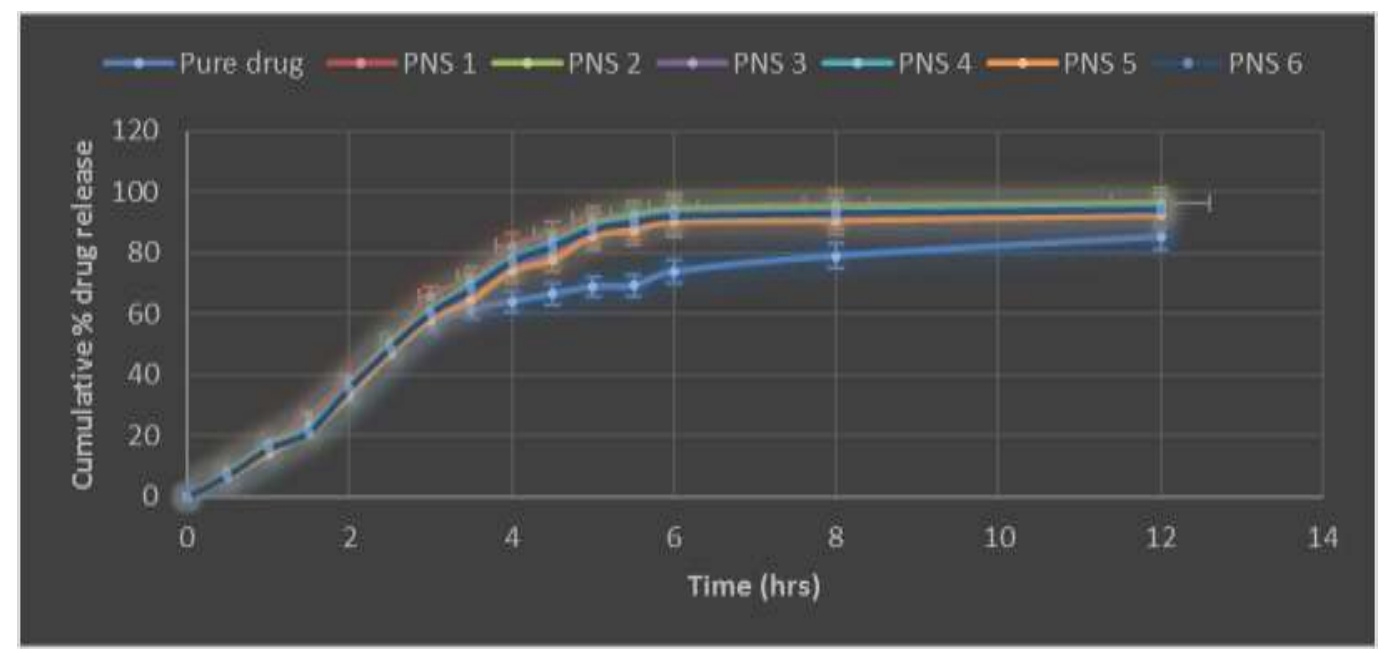

Figure 4: In vitro drug release profile of nanosuspensions prepared by nanoprecipitation method

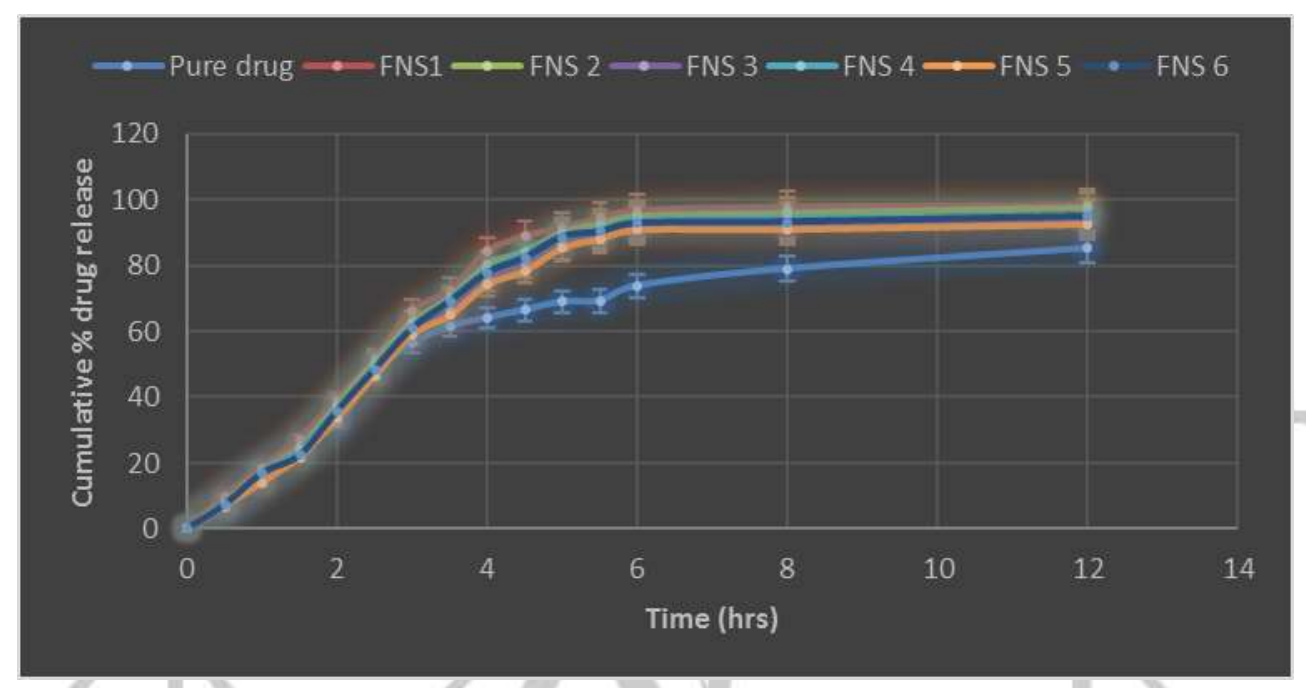

Figure 5: In vitro drug release profile of nanosuspensions prepared by nanoprecipitation method with cryoprotectants 


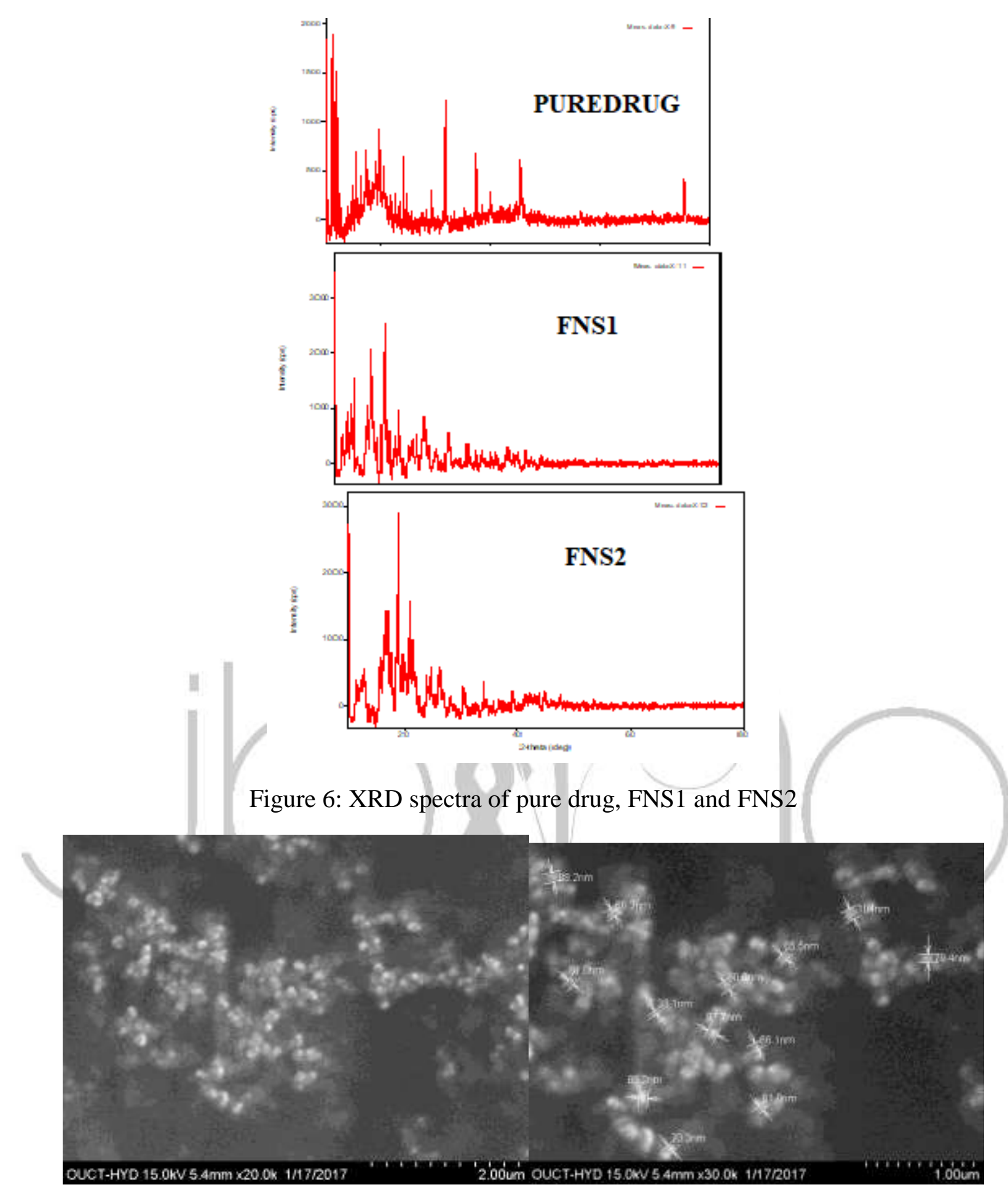

Figure 7: Scanning electron microscopic image of nanosuspension FNS-1 and FNS-2 


\section{CONCLUSION AND SUMMARY:}

Nanosuspensions, sub-micron colloidal dispersions, are a promising and potential technology to improve solubility of poorly soluble drugs. In the current research work, Azithromycin dihydrate, a poorly soluble BCS class II macrolide antibiotic was used as a model drug. Nanosuspensions of azithromycin dihydrate were attempted by nanoprecipitation method, wherein aqueous solvent containing stabilizers were added into non-aqueous solvent containing pure drug under continuous agitation, leading to finely divided nanoprecipitate of pure drug.

A problem encountered during post production and storage of nanosuspensions by nanoprecipitation technique, followed by freeze-drying was agglomeration of nanoparticles, causing changes in particle size and loss of vigor in improving solubility over a course of time. It is reported in literature that ice crystals cause damage to the basic physiochemical properties of nanoparticles. Hence, an attempt was made to protect the nanosuspensions from agglomeration by adding mannitol as cryoprotectant. It was reported that cryoprotectants partially solubilizes the nanoparticles so that they are less prone to puncture and interrupts the lattice formation of ice so that the formation of crystals is controlled.

In this work, 12 nanouspension formulations were developed with three different stabilizers- poloxamer188, poloxamer 407 and PVP, out of which 6 nanosuspensions were formulated using nanoprecipitation technique and 6 nanosuspensions were formulated using nanoprecipitation followed by addition of mannitol as cryoprotectant during freeze-drying process. The prepared nanosuspensions were evaluated, characterized and compared with each other by X-ray diffractometry (XRD), Fourier transform infra-red (FT-IR) spectroscopy, Scanning Electron Microscopy (SEM) images, In Vitro dissolution profile. FTIR studies confirmed that there was no distinguishable physical or chemical interaction between drug and excipients used for this study. SEM images showed the surface morphology of the prepared nanosuspensions to be accurate and size of nanosuspensions to be in nanometers. XRD data confirmed the crystallinity of the drug and slight changes in the crystallinity of azithromycin dihydrate in the formulations of nanosuspensions, to which improvement in solubility pattern can be attributed. Nanosuspensions containing azithromycin dihydrate and poloxamer 188 (FNS1 and FNS2) in molar ratios of $1: 1$ and 1:2, which are prepared by nanoprecipitation method including mannitol as cryoprotectant, were found to be better than other formulations. . In vitro studies reveal that there is marked increase in the dissolution rate of azithromycin in freeze dried nanosuspensions, when compared to pure azithromycin. By this study, it can be concluded that addition of mannitol or any other cryoprotectants during freeze-drying of nanosuspensions can prove beneficial in terms of improvement of bioavailability, change in crystallinity and stability profile. The oral bioavailability of the drug could be improved by more than two times due to improved aqueous solubility when compared to pure drug. 


\section{REFERENCES}

www.usfda.gov /azithromycin/

Merisko-Liversidge E, Liversidge GG. Nanosizing for oral and parenteral drug delivery: a perspective on formulating poorly-water soluble compounds using wet media milling technology. Adv Drug Deliv Rev 2011; 63(6):427-40.

Wang $Y$, Liu $Z$, Zhang D, Gao $X$, Zhang $X$, Duan $\mathbf{C}$, et al. Development and in vitro evaluation of deacety mycoepoxydiene nanosuspension. Colloids Surf B Biointerfaces 2011; 83(2):189-97.

Gupta NB, Singh K, Bhandari N, Sharma P. Significance of Nanocrystals in drug delivery. Int J Pharm Res Bio-science 2012; 1 (5):108-25.

Barret ER. Nanosuspensions in drug delivery. Nat Rev. 2004; 3:785-96.

Muller RH, Gohla S, Dingler A, Schneppe T. Wise D. Handbook of pharmaceutical controlled release technology. New York: Marcel Dekker; 2000. Large-scale production of solid-lipid nanoparticles (SLN) and nanosuspension (Dissocubes) pp. 359375

Bucolo C, Maltese A, Puglisi G, Pignatello R. "Enhanced ocular anti-inflammatory activity of ibuprofen carried by an Eudragit RS100 nanoparticle suspension". Ophthalmic Research 2002; 34(5): 319-323.

\section{H.Fessi, F.Puisieux, J.Ph.Devissaguet} S.Benita, Nanocapsule formation by interfacial polymer deposition following solvent displacement. Int J Pharm 1989; 55(1): R1-R4.
Barett. E. Rainbow, Nanosuspensions in drug delivery. Nautre reviews drug discovery, 2004. 3:785-796.

Venkata Bharadwaz Vedula, Maulick Chopra , Sonal Mazumder. Preparation and characterization of nanoparticles of carboxymethyl cellulose acetate butyrate containing acyclovir. Applied Nanoscience, 2016; 6(2):197-208.

Uma maheswari $R$, and Mullaicharam AR. Development and In-Vitro Evaluation of Nanosuspension Formulation Containing Acyclovir for the Treatment of Ocular Infections. Res J Pharm Chem Biol sci, 2013; 4(1): 463-480.

Pedro Fonte, Sandra Soares, Ana costa, José carlos andrade, Vítor Seabra, Salette Reis and Bruno Sarmento. Effect of cryoprotectants on the porosity and stability of insulin-loaded PLGA nanoparticles after freeze-drying. Biomatter, 2012;2(4): 329-339.

Higuchi, T. \& K.A. Connors (1965) Adv. Anal. Chem. Instrum. 4: 117-212. 
Cunha-Filho, M.S.S. \& L.C.L. Sá-Barreto Loftsson, T., M. Masson \& M.E. Brewster (2007) Rev. Ciênc. Farm. Básica Apl. 28: 1- ～(2004) J. Pharm. Sci. 93: 1091-9.

9. 